\title{
The Unreasonable Effectiveness of Abstract Metaphysics
}

Daniel Nolan. Final version published in Oxford Studies in Metaphysics (2015) 9: 61-88

One common style of objection to a metaphysical theory is to claim that even if the metaphysical posits of that theory were correct, they would not (and perhaps could not) explain the phenomena they were posited to explain, or that they would otherwise be useless for theoretical purposes. One early example of this sort of objection, I will argue, can be found in some of Aristotle's objections to the theory of Forms. There Aristotle seems to be objecting that a theory of Forms would be useless, or at least unexplanatory in an important way. I think this aspect of Aristotle's objections generalises: the same problems seem to arise for any theory that is realist about general properties and relations. This is somewhat ironic, since Aristotle himself seems to be a realist about universals.

The same kind of worry as the one I will diagnose has a contemporary incarnation, though as far as I can tell this contemporary cousin has no direct historical link to Aristotle's objections. The contemporary problem has been more widely discussed in the literature in philosophy of mathematics than the mainstream metaphysics literature: it is one aspect of the discussion about the so-called "Unreasonable Effectiveness of Mathematics". I think the parallel is that in both cases it is hard to see how abstract objects, whether numbers and sets or Forms and universals, can help with our theorising about concrete, particular, sensible objects. And I will claim that the answers available to this challenge in both the mathematics case and the case of general properties and relations will have important similarities.

A terminological note: I will refer to general properties and relations collectively as "universals" in this paper. ("General" properties and relations as opposed to particular property-or-relation instances, which I will call "tropes".) I will use the expression "Aristotelian universals" when I wish to talk specifically of universals as Aristotle conceives of them. 
This paper has three aims. One is to argue that some of Aristotle's arguments against Plato's Forms have affinities with some contemporary concerns about abstract objects. The second is to argue that concerns developed in the philosophy of mathematics about platonist theories of mathematical objects have clear application to theories of abstract objects more generally, particularly contemporary theories of universals. (Fortunately, I think there are good replies to these concerns in both cases.) The third aim is a more historical one, to offer an evaluation of the arguments of Aristotle's that the paper begins with. The next section discusses some objections by Aristotle to Plato's theory, and the penultimate section of the paper will return to Plato and Aristotle, with a discussion of whether Aristotle's objections are indeed worries for the theory of the Forms, and if so are they any less of a concern for Aristotle's own theory.

\section{Puzzling Aristotelian Arguments Against Plato's Theory of Forms}

Aristotle offers a number of arguments against the "system of Plato", particularly Plato's theory of Ideas of Forms, in Metaphysics A 987a-988a, 990b-992a, and some essentially repeated in Metaphysics M as well (1078b-1080a, and see also 1086a-b). Some of Aristotle's arguments are puzzling because they seem to attack features of a theory of Forms that cannot be found in Plato's dialogues: a "Great and Small" as a first principle generating the numbers, for example (987b-988a). Some have seen these objections to otherwise undocumented features of the theory of Forms as a sign that Aristotle is attacking aspects of Plato's esoteric doctrines rather than the exoteric doctrines, or that he is attacking aspects of theories of early Academics such as Speusippus or Xenocrates rather than Plato's own doctrines.

Other arguments are puzzling, not for these reasons, but because they seem to apply equally well to Aristotle's own theory of universals as they do to Plato's theory of 
Forms. ${ }^{1}$ It is this class of arguments I will be interested: these arguments seem to be designed to show that Forms are not explanatory in the way they should be.

The first argument (990b) is presented obliquely - Aristotle seems more concerned here to make fun of the friends of the Forms than to make the argument clearly. Aristotle says

$[\mathrm{I}] \mathrm{n}$ the first place in their attempt to find the causes of things in our sensible world, they introduced an equal number of other entities - as though a man who wishes to count things should suppose that it would be impossible when they are few, and should attempt to count them when he has added to them. For the Forms are as many as, or not fewer than, the things in search of whose causes those thinkers were led to the Forms; because corresponding to each thing there is a [homonymous $]^{2}$ entity apart from the substances (and in the case of nonsubstantial things there is a One over the Many), both in our everyday world and in the realm of eternal entities. (990b, 1933 p 63)

We might wonder whether this objection does apply to the theory of Forms we find in Plato's dialogues. In particular, it is not immediately obvious that there are as many Forms as there are sensible entities - many entities may share the same Form, after all. ${ }^{3}$ Provided there are many Forms postulated, though, it probably does not matter much whether there are as many as there are sensible entities. We might also worry about whether Plato saw the Forms as causes, but this seems more reasonable when we remember that Aristotle is using aitía (cause) to mean something close to what we mean by explanation: and it is surely true that Plato thought the theory of Forms helped explain

\footnotetext{
${ }^{1}$ Interestingly, Aristotle seems to admit as much about some of these worries in M (1086b), though it is unclear to me how much of his discussion he thinks "presents some difficulty both to those who hold the Ideal theory and to those who do not." (Tredennick 1933 p 249).

2 Tredennick translates ó ${ }^{2} v v \mu o ́ v$ as "synonymous" rather than "homonymous", which is idiosyncratic.

3 Aristotle did have some reasons to think that Plato was committed to the Forms being as many as the sensible entities, or at least "not less than" them. One interesting reason is that Aristotle holds that Plato is committed to "ideal numbers" as well as non-ideal mathematical objects: so there is a Form of One, a Form of Two, a Form of Three, and so on. We might still wonder about whether the cardinality of sensible entities is greater than the cardinality of the number series, but it should be clear why Aristotle would have thought that it has been demonstrated that there are at not-fewer Forms than sensibles once it has been demonstrated that there would be as many Forms as counting numbers.
} 
the sensible world. Finally, we may wonder whether Plato would have agreed with Aristotle that the sensible world was full of substances, in Aristotle's sense: but this does not seem important to the objection, since the thrust of it seems to be a challenge for explaining the entities in the sensible world, whether or not they are Aristotelian substances.

These reservations aside, Aristotle is pointing out something initially odd about the theory of Forms. When trying to explain the world around us, Plato postulates another realm of entities and tells us a lot about those other entities. But if anything this might seem to make the overall explanatory project more difficult. Now we do not just need a theory of the Forms and explanations of the Forms, but we still have our initial task facing us as well: we have all the explanatory burden we started with, plus a new realm which must also be explained. Interpreted this way, it looks like Aristotle is suggesting that the theory of Forms moves us further away from the goal of our theorising, rather than closer.

If this is the way to understand Aristotle's complaint, then it would seem to apply to any theory that postulates general properties and relations as well as particular objects. We start with a demand for a theory of shaped and coloured things, just societies, moving particles, or whatever: and then if we go on to in addition postulate shapes and colours, justice, movement, and a panoply of other properties and relations, we may seem to be only multiplying our explanatory tasks rather than resolving the ones we began with. (It is as if, as Aristotle says, we are set to count one group of things, and we introduce another group with as many or more objects in them and then have to count both.) Aristotle himself seems to postulate universals ( $\kappa \alpha \theta 0 \lambda \mathrm{ov}$ ), so he also faces this sort of objection: how does postulating these things help us in the explanation of the sensible things we started with, and why does it not just make our explanatory predicament worse? 
The second argument of Aristotle's I want to discuss is also one which, I will claim, is based on the complaint that Forms do not help to explain the sensible world, though it is put in terms of arguing that Forms do not "contribute" to sensible things:

Above all we might examine the question what on [E]arth the Forms contribute to sensible things, whether eternal or subject to generation or decay; for they are not the cause of any motion or change in them [the sensible things]. Again, they are no help towards the knowledge of other things (for they are not the substance of things, otherwise they would be in things), nor to their existence, since they are not present in the things which partake of them. If they were, it might perhaps seem that they are causes, in the sense in which the admixture of white causes a thing to be white; but... it is easy to adduce plenty of impossibilities against such a view.

Again, other things are not in any accepted sense derived from the Forms. To say that the Forms are patterns, and that other things participate in them, is to use empty phrases and poetical metaphors; ... ${ }^{4}$

Further, it would seem impossible that the substance of the thing and the thing of which it is the substance exist in separation; hence how can the Ideas, if they are the substances of things, exist in separation from them? It is stated in the Phaedo that the Forms are the causes both of existence and of generation. Yet, assuming that the Forms exist, still the things which participate in them are not generated unless there is something to impart motion; while many other things are generated (e.g. house, ring) of which we hold there are no Forms. Thus it is clearly possible that all other things may both exist and be generated for the same causes as the things just mentioned. (991a-991b, Tredennick pp 70-71)

\footnotetext{
${ }^{4}$ Here Aristotle lodges some objections to theories that take the connection between particulars and Forms to be a matter of resemblance or copying, reminiscent of objections to this theory discussed by Plato in the Parmenides 132c-133a. Aristotle's own text here can be read as suggesting that Plato does not literally take the connection to be a matter of copying or resemblance (presumably this is why Aristotle says it is merely metaphorical). But in any case the aspect of Aristotle's objection I am concerned with does not require the defender of Forms to maintain anything like a copying or resemblance theory of participation.
} 
Aristotle concludes with a complaint that the Platonists have ignored the crucial question of how the Forms cause sensible things: he uses the first-person plural "we" in directing this charge, but commentators agree that he talks about what "we" say because, here at least, he is talking as one of the Platonists/Academics, albeit one criticising their views ${ }^{5}$ :

In general, Wisdom is concerned with the cause of [sensible $]^{6}$ things, we have ignored this question (for we have no account to give of the cause from which change arises), and in the belief that we are accounting for their substance we assert the existence of other substances; but as to how the latter are substances of the former, our explanation is worthless - for "participation", as we have said before, means nothing. And as for that which we can see to be the cause in the sciences, and through which all mind and nature works - this cause which we hold to be one of the first principles - the Forms have not the slightest bearing on it either. (992a, Tredennick pp 75-77) ${ }^{7}$

Again, when reading the four connected passages above, we might be concerned about whether Aristotle correctly characterises Plato's view of Forms, or at least the view of Forms expressed in his dialogues. Aristotle, here and elsewhere, seems to claim that defenders of Forms reject Forms for artifacts: but this is hard to square with the discussion of Forms of beds and tables in Republic 10, for example. Aristotle rejects the claim that ordinary things participate in Forms by being copies of those Forms or similar to those Forms, and while some have interpreted Plato as maintaining that they do, I am inclined to think that at least by the Parmenides and the Sophist Plato does not hold that

\footnotetext{
${ }^{5}$ In one version of Metaphysics A, the version Alexander of Aphrodisias used, Aristotle even says "We say in the Phaedo"! (Alexander 1989 p 115)

6 Tredennick translates Aristotle here as talking of "visible things" rather than sensible ones: but $\varphi \alpha v \varepsilon \rho o ̀ v$ here might also be better translated as "manifest things", which would produce an aphorism that is less objectionable. (Why would wisdom be any less concerned with things that cannot be seen?) I have rendered it "sensible", here, since it is clear from context that Aristotle has in mind the sensible things, particularly substances, about which he has been complaining earlier that the theorists of the Forms do not explain. This is a slightly less literal rendering of the word than either "visible" or "manifest" would be, however.

7 In presenting this part of 992a as part of the argument of 991a-b, I am making the disputable interpretive assumption that in the second quotation Aristotle has returned to general criticisms of theories of Forms, rather than just criticism of those who make the additional claim that Forms are all numbers. Alexander reads Aristotle this way as well (Alexander 1989 120.20-21).
} 
view of participation. In any case if Plato did insist on that as part of the theory of Forms that theory faces serious problems, so I am happy to suppose for these purposes that Aristotle is right that participation is not a matter of similarity or copying.

As before, these details do not seem to me crucial to one of the main lines of argument in this passage. The main line of argument is that Forms would not help to explain the sensible objects that they are supposedly related to. Contra Plato, Aristotle thinks that they could not be causes or explanations of motion or generation; of the existence of sensibles, or even of our knowledge of the sensibles. Finally, Aristotle thinks we cannot allow that sensibles depend on the Forms, or are derivative from them. Aristotle seems to be suggesting that Forms cannot explain sensible particulars in any way.

I take it that what I earlier referred to as Aristotle's "first argument" — the argument about multiplying entities to be explained - is a subsidiary way of making this point, or making it vivid. Presumably the only way that postulating new entities could be an advance in our explanatory project is if the theory produced by this postulation did so well in explaining the original explanandum that it was worth the burden of taking on the challenge of explaining the new entities. Otherwise introducing new things that themselves require some explanation is going backwards. In suggesting that postulating Forms as well as sensible objects is analogous to being set a task of counting $n$ things, and adding $m$ entirely distinct things to them before starting to count, Aristotle is suggesting that Forms only add to our explanatory burdens without relieving any of them.

In one respect the question "what do Forms contribute to sensible things" is a strange question for Aristotle to be asking. One of the four "causes" Aristotle distinguishes is formal causation, and indeed says elsewhere in the Metaphysics $(\Delta, 1013 \mathrm{~A})$ that the

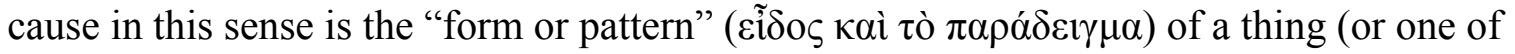
the genera of these, or parts of these). Presumably Aristotle is using "form" here in a less technical sense, or at least a different technical sense, than when he is discussing Plato's views. Still, one might think it would have occurred to Aristotle that his Academic opponent might say that Forms explain sensibles in the way that forms do: and if 
Aristotle were prepared to concede this much, it seems he would already have his answer to the question of "what the Forms contribute to the sensible things": on this line of response, they are the formal causes of those things.

One thing that is very plausibly happening is that Aristotle thinks Forms cannot be explanations in all the ways he thinks Plato wants them to be (the overall point of his discussion in Metaphysics A is that previous thinkers have gone astray in not properly understanding the four causes). Another thing that might be going on is that Aristotle thinks that Forms, conceived of as Plato conceives of them, fail to have the features that would make them fit to be formal causes, in Aristotle's sense. I suspect that what we have in Metaphysics A is a list of objections that Aristotle developed in more detail elsewhere (some other objections to Plato's theory of Forms briefly offered in Metaphysics A, for example, do seem to have been developed further in his On The Ideas, at least if we are to trust Alexander of Aphrodisias (e.g. 79.4 and 98.23-25 in Alexander 1989)), and without the further detail it is sometimes hard to tell exactly what Aristotle had in mind. Nevertheless, let us examine the two suggestions about what is going on here in turn.

If Aristotle wanted to complain that Plato did not clearly distinguish Aristotle's four causes, that seems a fair complaint. And it is plausible that Plato did not do much to argue, in the Phaedo at least, that the Forms are efficient causes of generation and change. Aristotle also seems to be attributing the view to Plato that the Forms are efficient causes: but while Plato in the Phaedo can be read as saying the Forms are causes of everything, including generation (Phaedo 100), it is not at all clear to me that this is a claim about efficient causation: just as Plato in the Sophist seems to be saying that moving things move in virtue of participation in the Form of Motion, it is plausible that Plato in the Phaedo is only claiming that Motion is the formal cause of motion. (Aristotle may well reject the claim that there is a general formal cause of motion, but that plays no part in his argument here.) Perhaps Aristotle is reading Plato as claiming that Forms are the only causes (as opposed to e.g. the most important form of cause that was the object of Socrates's search). So let us grant to Aristotle (for the sake of the 
argument at least) that Plato's Forms are not, in general, good candidates to be material, efficient or final causes of material things. This does not yet capture the full extent of Aristotle's complaint, it seems to me. ${ }^{8}$

Aristotle also seems to think that Platonic Forms would be unfit to contribute to a thing's existence in any way (and would not merely be unfit as a efficient cause of generation of a thing, for example). My conjecture is that Aristotle thinks they are unfit to be formal causes because they are not "in" the objects. If the primary formal cause of a thing is its substance, for example, and if for Aristotle substances must be "in" objects, then if Aristotle is right that Platonic Forms would not be "in" their objects, they cannot serve as the primary formal causes of entities. That Aristotle thinks that substances must be "in" their objects is shown by his assertion that the two cannot be "separated" (Tredennick p 69): he uses "in" and "separated" as antonyms here. ${ }^{9}$

That substances are the ultimate formal causes for Aristotle is more conjectural. ${ }^{10}$ Aristotle characterises formal causes differently in different places: the "form or pattern; that is, the essential formula and the classes that contain it" (Metaphysics $\Delta 1013 \mathrm{a}$ ), the "form or characteristics of the type, conformity to which brings it within the definition of the thing we say it is" (Physics B 194b) the "essential nature of the thing in question" (Physics B 198a). ${ }^{11}$ This last characterisation suggests that the primary formal cause is the essence (though broader genuses that the essence belong to are clearly formal causes as well, as can be seen in the first characterisation, they seem to be so derivatively). It is a further interpretive leap to claim that essences of substances are the substances

\footnotetext{
8 The next page or so contains particularly controversial interpretive claims about Aristotle's views. The connections between form, substance, essence, universals, particulars and sensibles are among the most controversial when intepreting Aristotle's metaphysical doctrines.

${ }^{9}$ See also Metaphysics M 1086b where Aristotle seems to be saying that it is separation in particular (i.e. not being "in") that is the source of some troubles for Plato's theory of Forms. Aristotle seeing the issue of separation dividing him from Plato appears in a number of places in Aristotle's work: see Fine 1984 for a thorough discussion.

10 Frank Lewis is one author who defends the view that Aristotle identified the forms of objects with their substances (Lewis 1991, especially ch 6). If that is right, that at least strongly suggests that substances are the ultimate formal causes: it would be at least strange if something other than forms were ultimate formal causes.

11 Aristotle seems to use "form" in a very wide variety of ways across his writings: see Studtmann 2008 for a range of examples and an interesting suggestion about how they might be unified.
} 
themselves, though Aristotle's remarks in Metaphysics $Z 1028 \mathrm{~b}$ make it hard to deny that he holds that the substance is at least sometimes the essence.

Even if we allow that the primary or most fundamental formal cause of substances is the substance (which is presumably specified by means of the real definition of the substance), then even if we also grant that Platonic Forms cannot be substances, we still have not got an argument that Forms cannot be formal causes: since even if substances are the primary or ultimate formal causes, Aristotle clearly allows that other entities can be formal causes too, such as the "classes" which contain the essential formula. Aristotle's universals seem to fit in here: they are not substances (see Metaphysics $Z$ $1038 b-1039 b$ ), yet things like "number in general" can be formal causes (Metaphysics $\Delta$ 1013a), which certainly suggests universals can be formal causes even by Aristotle's lights. ${ }^{12}$ Aristotle does seem to think that universals are "in" those entities which fall under them, for what it is worth, but without an argument why this must be so we do not have an argument that the Forms' not being "in" the sensibles rules them out from playing the formal causal role that universals do.

Again, if I may conjecture, my guess is that Aristotle thinks that the universals are formal causes only derivatively - they can only be formal causes by being downstream of the primary formal causes which are "in" substances. Some evidence for this is the way he apparently contrasts his own view with one according to which universals are "in the truest sense a cause and a principle" (Metaphysics $Z$ 1038b, Tredennick p 377): if universals are not "in the truest sense" a cause maybe they are only a cause secondarily or derivatively. Since Platonic Forms are not downstream of sensible substances in the right sort of way, Aristotle might think that they are unfit to be formal causes even derivatively. He does not present such an argument in Metaphysics A (or elsewhere in his surviving works, so far as I know), but such an argument, together with an argument that non-substances can only be formal causes of substances derivatively, would rule

\footnotetext{
12 Fine 1993 claims Aristotle identifies his forms with Aristotelian universals (p $251 \mathrm{ftnt} 33$ ). This goes beyond what I am comfortable claiming: I claim only that Aristotle's universals are candidates to be identified with Aristotle's forms, and in any case Aristotelian universals are supposed to be able to be formal explanations.
} 
Platonic Forms out as candidates to be formal causes. Presumably, of course, there must be some entities Aristotle is happy to call "forms" which can be formal causes, in light of Metaphysics $\Delta$ 1013a and Physics B 194b. ${ }^{13}$

As far as Aristotle exegesis goes, it may be important to point out these differences in what sorts of objects Aristotle is willing to allow to be causes and what sorts cannot be. But beyond the goal of understanding Aristotle, we might think that Aristotle is pointing to general kinds of problem here, which both he and the Platonist should try to find satisfactory answers to. One problem is what explanatory role can be played by Forms, or Aristotelian universals, or indeed anything that is supposed to play the role of general properties and relations. We should not rest content, either, with the mere postulation of a type of explanation, "formal explanation", which is such that by definition Forms or universals explain in that way: we would want some assurance that these explanations are genuine ones.

In fact, there seem to be two connected challenges we can draw from Aristotle's objections. The one made most explicitly is that the Forms do not explain sensible particulars. But only slightly more implicit is the charge that Forms are useless for good theorising. Aristotle may not have distinguished the two since he seems, in the Metaphysics at least, to take the aim of theorising to be supplying causes/explanations (Metaphysics A 992a). The second challenge is more serious, at least in principle: if Forms did not explain, that still leaves open that they might perform some other useful theoretical function, but if they are altogether useless for good theorising, the case for rejecting them is strong.

I will return to the issue of what Plato and Aristotle can usefully say to defend the explanatoriness and usefulness of Forms or Aristotelian universals, respectively. Before

\footnotetext{
13 Lewis 1991 offers an intricate alternative to this picture, whereby, inter alia, forms are universals and substances, but are not the individual substances, and has an alternative diagnosis of Aristotle's objection here against Plato's theory of Forms. Despite the differences, Lewis's interpretation of Aristotle fits well with the main point I want to make, that Aristotle is presenting challenges that are not only objections against Plato's theory, but which require a response from Aristotle's own view. If Lewis is right, this is a response that Aristotle develops in later books of the Metaphysics.
} 
doing so, though, I want to connect these ancient problems with a contemporary problem. Platonists about mathematical objects, in the contemporary sense, believe in the literal existence of abstract mathematical objects like sets, numbers, functions, groups and the rest. They face a challenge to explain why it is that postulating all of these abstract entities helps us in our theorising about the non-mathematical world, in particular the aspects of the world studied by the natural sciences. In looking for the utility of contemporary postulation of abstract objects, we can look to the debate in philosophy of mathematics to turn up some useful options in helping us to solve the ancient problem. And we can see that at some level of generality the ancient problem is a problem for contemporaries who postulate abstract objects.

\section{The Unreasonable Effectiveness of Platonic Mathematics}

This way of understanding Aristotle's objection has important similarities to a puzzle about mathematics raised by Eugene Wigner (Wigner 1960). Let me present a version in my own words. Suppose you were primarily interested in the behaviour of physical objects: moving bodies, or electric fields, or water in a pipe, or for that matter populations of animals, growth of wheat, or shopping patterns during the year. It turns out that an amazingly good way to do this is to engage in mathematics, including employing mathematical techniques which were often developed with no thought to the application at hand. How could this change of subject to numbers, functions, equations and the rest help us with wheat growth or predicting which pipes full of water burst?

I should note that this is not the only puzzle raised in Wigner's paper and subsequent discussion: Wigner seemed more concerned with the puzzle of how mathematics could have turned out to be so useful, in the many ways that it has, for the natural sciences, along with other puzzles about how the practices of the natural sciences have been so successful. Nevertheless, the puzzle of how shifting to an apparently very different subject matter can help at all is presumably prior to the question of how it can help so much. 
This puzzle is a challenge to be addressed by various philosophy of mathematics: those who reject the truth of mathematics are sometimes challenged to explain how it could be so useful if it were not true. But I agree with Mark Colyvan (Colyvan 2001) that it is also a problem for mathematical realists and platonists (in the mathematical sense): if talk of numbers, sets, equations, functions and the rest is talk of a special realm of abstract objects (i.e. numbers, functions etc.), and of special relationships those objects stand in (being the domain of a function, or the exponentiation of a number or a variable, etc.), then how does theorising and reasoning about all that stuff help us with burst pipes and growing wheat?

This looks like a version of Aristotle's first puzzle, as applied to platonistic mathematics: by postulating a new realm of objects and making claims about them, we have doubled our epistemic and explanatory burdens - now we are set the task, not only of finding out all about the concrete particular physical things, but about these abstract mathematical things as well. Viewed like that, it seems like we have made things worse, not better.

If one strand of Aristotle's objection is a close analogue of this puzzle about platonistic mathematics, the Lovers of the Forms might well be comforted. After all, however much we might be puzzled by this feature of mathematics, no philosophers I know of want to conclude that we should stop employing mathematics in the physical sciences (or other sciences, for that matter). We should be confident that somehow mathematics is useful in investigating concrete physical phenomena, even if we remain puzzled how. Likewise Plato might retort that however puzzled we might be by our ability to use reasoning about the Forms to help us understand the physical world, we should not respond to this puzzle by rejecting the existence or usefulness of the Theory of Forms.

Things are not quite this simple, of course. There is no immediate guarantee that Forms will be useful in whatever sense mathematics is useful - the fact that one kind of abstract theoretical posit is worth making is not carte blanche for positing whatever we like. Plato would ideally need to show that Forms are useful in either the same sort of way that mathematics is, or in some alternative way, rather than just rely on being in initially 
promising company. For now, though, let us worry about contemporary partisans of general properties and relations: they too would need to have some reason to suppose universals are useful in whatever sense mathematics is useful before the fact that the problem arises in the mathematical case should be much comfort to them.

For another thing, there is the issue of whether mathematics and a theory of universals are meant to help us in the same way in grappling with the sensible world. Aristotle seems to be asking about supplying explanations of sensible phenomena, and one might think that mathematics is very useful for prediction and summarising while doing no explanatory work in the sensible realm, or very little. (See Daly and Langford 2009 for a recent argument that mathematics is not explanatory of physical phenomena.) If we reject the claim that mathematics can explain sensible phenomena, we would need to concede Aristotle's first objection though we could still look for a useful role for mathematics.

Likewise, even if a defender of universals had to concede that they did no explanatory work, she would still have something worthwhile if she could show they were important for some other theoretical purpose. One way to do this might involve showing that they are good in whatever other way mathematics is supposed to be, though this would not be a trivial undertaking. Mathematics seems to play an important role in predictive sciences, for example (this is one reason engineers get out calculators before building things): and it is less obvious that we need to talk about Forms to do successful prediction. Of course, given the widespread use of talk about properties and relations, perhaps a case can be made for universals here, even though it is a less obvious one.

In any case, I suspect Plato at least would want his theory of Forms to be explanatory, and so will many who postulate universals. They do not seem to be postulated just as aids to prediction or calculation: examining them is supposed to yield understanding of the world around us. So Plato, and many of his contemporary counterparts, would probably want a response to both charges: not only an account of a theory of Forms which shows why it is not useless when trying to grapple with the world of sensibles, but also to show how the Forms and facts about them can explain things in the world of 
change and decay. A number of contemporary believers in abstract mathematical entities also want to be able to defend the explanatoriness of mathematics as well as other usefulness mathematics might have for theorising: see Colyvan 2001 and Baker 2005 as examples. Presumably Aristotle is also committed to the explanatoriness of universals (they are hardly causes in his sense unless they explain). So it is worth keeping in mind both the challenge involving explanation and the more general challenge involving usefulness.

Another hurdle to be faced by a realist about universals who wants to ride on the coattails of mathematics is that the puzzle about the applicability of mathematics only looks analogous to the applicability of a theory of Forms (or other theories of general properties and relations) if we think mathematics is about an abstract realm of special objects and their features in the first place. If it turned out that mathematical platonism was a bad theory of mathematics (and especially if e.g. one of the rival hypotheses about mathematics explained the amazing applicability of mathematics better), then the effectiveness of mathematics in theories of the physical world would be little comfort to the realist about universals. So it would be a mistake to move too quickly from the undoubted usefulness of mathematics to the conviction that, somehow, theorising about a realm of abstract entities can be a good part of a theory of things in the sensible world.

So both in the case of platonistic mathematics, and realism about universals (/Forms), it would be useful to have a worked-out response to the charge that these theories are not explanatory, and also to the charge that they are not useful at all in theorising. I will not try to develop a full response here: instead, I will lay out what seem to me important alternative responses, and indicate where I think the most satisfying sort of response will be found.

\section{Responding to the Usefulness and Explanatory Charges}

Whether it was what Aristotle had in mind or not, it seems that we have an interesting objection to theories of general properties and relations here. If my purpose is to come 
up with a good theory of "sensibles", or particular things in the world of individual things in time and space, how does postulating a realm of abstract universals help? Indeed, why is it not just making the theoretical project harder, since not we not only need to account for the entities we started with but for a somewhat mysterious realm of additional entities as well?

As we have seen, there are two versions of this challenge: the stronger one raises the question of what use universals are at all when dealing with particular objects, while the second is the more specific challenge of what use they could be in explaining anything about particular things. Let me discuss some initial options for responding to these challenges which I do not think go far enough, before ending with some more constructive remarks about how I think the challenges are best faced. I will conclude with a brief discussion of how Plato's theory of Forms and Aristotle's theory of universals fare against our updated challenge: I will argue that Plato's theory of transcendental Forms seems to be able to meet the charge just as well as Aristotle's alternative theory of universals. Indeed, it may be that in some respects it is Aristotle's theory that has a harder time of things here.

I shall not discuss in any depth the option of conceding that universals are not of any use in theorising about, or explaining, particular matters of fact. That response is, of course, an interesting one, as is the response of holding that platonistic mathematics could not be useful for any other purpose. This sort of response to Aristotle's charge may well also have been historically significant, since Aristotle's rejection of Platonic Forms may have motivated some (e.g. Abelard) to read Aristotle himself as a nominalist, or as something close to one.

The first line of response to our challenge I wish to discuss is a somewhat "conceptualist" response, but not necessarily in the sense of taking properties and relations to be metaphysically dependent on thinking. It is rather that the role of explaining particular entities played by postulating universals is one of explaining intelligent activity: general properties and relations are postulated primarily to help explain thought and language. 
We might postulate universals as the semantic values of predicates, for example, or as part of a theory of mental content. These seem to be the primary intended roles for Frege's concepts, for example. Postulating universals helps a theory of meaning in a number of ways - one obvious way is by providing referents for abstract nouns ("justice", "piety", "redness" and so on), and being able to quantify over the meanings of predicates has proved invaluable in systematic semantics. Of course, this defence is not uncontroversial: there are alternatives to postulating properties and relations when trying to provide a systematic semantics or a systematic theory of mental content. But postulating general features of the world has a natural home in the prediction and explanation of our use of general expressions and our having of general thoughts. ${ }^{14}$

This line of response is compatible with taking the universals themselves to have no dependence on mind or language: Frege's concepts, for example, are not entities generated by our thought or words. It is rather than the role they play in explaining the sensible, particular world is via explanations of our mental lives and voluntary activity (including communication). A full dress version of this response would presumably also explain how it is that our intelligent activity can involve universals, but even without this further story, this sort of theory is a response to the charge that universals would be explanatorily idle (or idle insofar as we want to explain particular entities, in any case). Humans and their activities are presumably part of the sensible world, after all.

Mind and language are important, of course, and being able to help explain important parts of what we do is a valuable enough contribution to be worth a theoretical postulation or two, in my view. But while this answers the letter of the challenge, showing one way that a theory postulating universals can explain some sensible particular things and events, it still does not go as far as I would like. Theories about mind and language are not the only places where we talk about universals: an engineer who studies geometry does not learn about shapes and figures primarily to apply that learning to

\footnotetext{
14 An example both less contemporary and more Aristotelian of employing universals to explain mind and language is that of Aquinas. His account of cognition in terms of a universal being present in one way in the mind and in another way among its instances plays a significant role in his theory of mind, and presumably he would think whether and how a given universal is in a mind can make a difference to what the thinker says and does.
} 
people thinking about and talking about shapes, but to inanimate objects with shapes and dimensions. In the mathematical case, one use for mathematical knowledge is to predict and explain what mathematicians and other people employing mathematics will think and say: but that does not suggest a puzzle about unreasonable effectiveness in the way that the use of mathematics in physics does. We seem to be concerned about properties and relations in a much wider range of inquiries, so it seems to me that we should not be content to point out their use in theories of mind and language but to see what can be said about their use in theories of particular objects in general.

So if we raise our sights to demand a story about the usefulness, and perhaps even the explanatoriness, of universals and mathematical objects across the board (or at least across the natural sciences), is there anything persuasive for the realist to say? Some things the realist about platonist mathematical objects may want to say can look like reducing the puzzle of appeal to mathematical objects to the puzzle of appeal to general properties and relations. For example, some try to explain the usefulness of appeal to mathematical structures by pointing to shared structures between some mathematical structures and some physical structures. One way to understand this is that it is claiming that some structures in pure mathematics (particular objects in pure mathematics) stand in mathematical relationships with some impure mathematical structures (particular mathematical objects with physical things in their transitive closure). This is, for example, what French 2000 p 106-7 and Beuno, French and Ladyman 2002 pp 504-6 do when offering an explanation of the application of mathematics to physics, with partial homomorphisms between pure mathematical structures and classes of models employed by physics, where the models are themselves impure mathematical structures. But that does little to explain the connection between the mathematical realm and the nonmathematical realm: it rather points out a connection between one piece of the mathematical realm and another. A more tenable approach, it seems to me, is to approach applicability of mathematics to the physical world in terms of relations between general features of mathematical structures and general features of physical structures e.g. a similarity relationship between a mathematical metric, on the one hand, and a relation between spatiotemporal intervals (or indeed between spatiotemporal relations) on 
the other. Armed with information about the mathematical structure, together with information about how it is similar to a non-mathematical entity, we can infer information about the non-mathematical entity.

Showing how we can link mathematical entities and non-mathematical entities in this way is a promising approach to showing the usefulness of mathematics, though more would need to be said about why bringing mathematics into our theorising is more useful than just reasoning about the non-mathematical object directly. But the nonmathematical objects mentioned here are general properties and relations (in this example, relations on spacetime intervals). So if this line of response is taken, justifying the use of mathematics in e.g. the natural sciences by pointing out the connections between mathematics and the general properties and relations of interest to the relevant science, then we are still left with the challenge about universals: how does talking about general properties and relations and their features help us with particular entities: particular wheat crops, burst pipes, cloud chambers, etc.?

Another respect in which the challenges about universals might be seen as intimately connected with the challenges about mathematical objects is that some theorists think the role of universals are played by ordinary mathematical objects: that properties, for example, ought to be identified with sets of their instances, and relations identified with (ordered or un-ordered) n-tuples of the things which stand in them. I think this is the best way to understand Quine's view: his view is not that there are no general properties and relations, but rather that there are such things, and they are sets (see Quine 1980). If this is right, then connecting other mathematical structures to the general properties and relations of objects of interest is not really breaking out of the mathematical realm at all: it is merely associating one mathematical structure with another. So perhaps the applicability of theories of universals just is the question of applicability of mathematics, above appearances notwithstanding.

So the issues about applicability of mathematics and applicability of universals may receive similar solutions, and indeed may be aspects of the same problem in one way or 
another. One very general thing to say about the use of postulating universals is that statements of connections between universals, and generalisations about universals, can capture information about particular objects that is very difficult to capture through talking about the particulars directly. It is not that we need universals, in any obvious way, to generalise. "All wheat requires water to grow" is about wheat, and water, but not the property of Being Wheat or the property of Being Water, at least not in any direct way. We can even generalise about wheat and other kinds of crop without dragging properties into it: "cereal plants all require water to grow" generalises over wheat and other kinds of cereals in some sense, but not by talking explicitly about properties or kinds.

However, some generalisations do explicitly talk about properties or kinds. "More than eight kinds of cereal crop were grown in medieval England", for example. Some of these claims can be paraphrased with some success, if a little clumsily: "there is a set of eight past cereal plants, all grown in medieval England, such that each is different-kinded from the others", or something of the sort, and even the reference to sets is eliminable here. Even here the paraphrase is clumsy. Once we get to claims like "the mass-energy of any closed system is constant" "the area of a circular region is equal to $\pi$ times the square of the length of the radius", it is harder to paraphrase these successfully without reference to properties and relations or mathematical objects (and maybe areas and lengths, whatever they are) respectively. Claims entirely about properties and relations are available, such as "red is more similar to orange than to blue": and while that is explicitly about colours (apparently general properties), it gives us guidance, together with other things we believe, about what to expect when looking at red and orange and blue things. (This traditional example is due to Pap 1959.)

It is at the very least not easy to come up with systematic paraphrases of many of these useful generalisations that invoke mathematical objects or universals, which preserve their usefulness but which are explicitly only generalisations about particular concrete entities. Nominalists might still disagree about whether paraphrase is feasible, and if it is feasible whether it would be preferable, for at least some important purposes. But we can 
at least see that helping ourselves to the claims about universals and mathematical objects gives us a grasp on generalisations that have useful consequences about particulars but where those useful consequences are difficult to sum up directly.

Some nominalists, particularly instrumentalists and fictionalists, may agree that the generalisations in terms of properties and relations or mathematical objects are useful, while still denying that we are justified in believing them true. These fictionalists will not, I take it, disagree with the point I am making here, which is that these particular claims are $u s e f u l$ in theorising, even if they try to accommodate the usefulness of the claims without admitting their truth. And this defence of usefulness, remember, is not being deployed here as an argument directly for realism about universals or platonism about mathematical objects: it is rather being deployed to respond to a charge that it needs to be shown how such postulates are useful. It may be that this account of usefulness is one that non-realists can so far share - a defence available to many views is no less a defence for that.

This might not be the only defence of usefulness available (and I will briefly discuss a more ambitious albeit stranger defence below). There remains a question about whether universals, or for that matter mathematical objects, can serve in explanations. It is difficult to resolve this question to everyone's satisfaction largely because the question of what makes something a good explanation is itself so murky and controversial. The deductive-nomological model of explanations, where an explanation is an argument with a law-statement as a major premise and the explanandum as a conclusion, is no longer popular, and rightly so. But there does not seem to be an orthodoxy yet to replace it. One popular movement has been to treat explanation as giving the (efficient) cause of the thing explained, or more generally causal information about the explanandum, but on closer inspection nearly every such theory of explanation restricts its scope to avoid being a general theory of explanation. (See Jenkins and Nolan 2008 for discussion of this, especially footnote 2 and pp 113-115.) Whether mathematical entities or universals could explain sensible matters of fact, on simple versions of this picture, depends on whether properties and mathematical objects could be causes. Even here, the case is not 
hopeless, since there does seem to be property causation (heat can cause heatstroke, for example, and plausibly can cause particular events of heatstroke - a doctor can diagnose the patient's vomiting and headaches as due to excessive heat).

On a more sophisticated causal theory of explanation (e.g. Lewis 1986), all that would be required for mathematical entities or universals to play a role in explanation of particular events would be for talk about them to be a useful way of conveying information about the causal history of those events: and mathematics and property talk certainly seem to be useful ways of conveying information about these matters. (Lewis is officially silent on explanations of matters other than particular events, but extending his theory in the obvious way gives a theory where anything is explained by giving information about its causal history, and whatever the drawbacks of such a general theory, it seems at least friendly to mathematics and properties and relations playing a role in explanations.)

Other theories of explanation, such as theories of explanations as unificatory (Friedman 1974, Kitcher 1989) would presumably be friendly to counting mathematical and universals-involving explanations as genuine, since mathematics and property-andrelation talk seem to earn their bread and butter in providing general, unified accounts of the phenomena. Theories that are very catholic about what sorts of information can be invoked in explanations, such as van Fraassen's (van Fraassen $1980 \mathrm{ch}$ 6) will easily accommodate, at least in principle, citing properties, relations, and mathematical matters in explanations. Nevertheless, the topic of whether mathematical objects and mathematical claims can do explanatory work remains controversial: though one odd aspect of the controversy is that those hostile to mathematical explanation often describe a role for mathematics that would make it straightforwardly explanatory on several common models of explanation such as Kitcher's or van Fraassen's. (See Daly and Langford 2009, and references therein, for a defence of an "indexing" role for mathematics which they see as supporting the claim that mathematics is non-explanatory. It seems to me that if mathematics played this role that would vindicate the role of mathematics in explanation of physical phenomena.) 
Most general theories of explanation vindicate an explanatory role for mathematics, and the same sort of explanatory role is standardly available for universals as well. While the fact that theories of explanation are very controversial means that it is unlikely to be made uncontroversial that mathematics or universals can be invoked in genuine explanations, if any of the main contending theories of explanation are on the right track, the prospects are good that the correct theory of explanation will not preclude employing mathematical objects and universals in genuine explanations.

The use of universals to capture information about particulars that is difficult to capture otherwise is an important and to my mind rather compelling argument for postulating them and employing theories that do. (Though to show that we should go beyond mere instrumentalist or fictionalist approaches to talk of properties and relations would require much more argument than I have offered here.) The usefulness of citing properties, relations, and mathematical objects in explanations also seems to me important, though more controversial. But I think there is a third, more Platonic, argument for postulating universals as well: and postulating them in a way that makes objects seem to depend on them rather more than they need to for the previous defence to work. This conception of universals makes them explanatory in a much more metaphysical way than the options so far considered.

This third approach involves the question of whether we can explain predication by appeal to properties. One approach to predication is to take true predications as basic. For example, it might just be a fundamental matter of fact that electron $E$ is negatively charged, with no further metaphysical account forthcoming. Another, more traditionally realist, is to supply a further explanation: electron $E$ is negatively charged because it has a particular property - negative charge, or perhaps a determinate of it such as the property of having - $1 e$ charge. It is controversial whether this further explanation is worth having: David Lewis is one who argues it is not (Lewis 1983 pp 21-24). But it seems to me that there are advantages to explaining a lot of ordinary predication in terms of properties and relations instantiated by entities. 
One putative advantage is that we have much less unanalysed predication: we do not need "is negatively charged" or "is negatively charged to degree $-1 e$ " as undefined primitives in our theory, since it is a matter of standing in the instantiation connection to the relevant property. Since "is positively charged" is likewise explained in terms of instantiation and the relevant property, we have at worst one undefined predicate ("... instantiates...") rather than two. Of course, this supposes that identifying the properties of negative and positive charge (or whichever are taken to be basic) can be done without using primitive predicates that apply to properties and relations themselves. ${ }^{15}$

Another putative advantage is that it does more metaphysical explanation in terms of ontology rather than ideology. There is something in virtue of which two electrons $E_{1}$ and $E_{2}$ are similar: their shared property. Of course, those who think that it is fundamental that $E_{1}$ and $E_{2}$ are negatively charged can agree that they share a property but for that view, it is not because they share a property that they are similar: rather, presumably, they share a property because they are both negatively charged. It is a difficult matter to say why we might prefer to explain the world in terms of ontology rather than primitive predicates: sometimes "truthmaker" intuitions are appealed to, or sometimes other arguments are offered, and not just by those sympathetic to this sort of analysis of predication: when Quine argues, in effect, that primitive second-order logic is less preferable than set-theory one thing that is going on seems to be a preference for cashing out commitments ontologically, though no doubt this is not the only thing going on here.

If trading in primitive predicates for extra ontology is an advantage at all in these sorts of cases, it is plausibly an explanatory advantage. Its motivation seems to be some sort of simplicity consideration, or something analogous to a simplicity consideration: and it

\footnotetext{
15 A trope theorist might want to claim the advantage of analysing predication without invoking general properties and relations: $E_{1}$ being negatively charged could be explained in terms of $E_{1}$ 's relation to its negative charge trope. The trope theorist might still face a challenge of explaining in ontological terms what it is for $E_{1}$ and $E_{2}$ to share a quality, or their being similar, or similar general matters. But the main point of the discussion in the text is to say that the general properties and relations may be able to do a certain kind of useful explanatory work, not that they are the only means of doing that work: if trope theorists can do that work without the general properties and relations, this point would be unaffected. Thanks to Michael Rota for discussion of this issue.
} 
does not seem to be done for the sake of prediction or other non-explanatory goals of a theory. So this final motivation, if accepted, seems to help with the project of showing that postulating universals is explanatory, as well as the project of showing that such postulation is theoretically useful somehow or other.

One challenge to this way of thinking is that this "ontology first" approach still suffers from primitive predication or "unanalysed predication", because of the instantiation predicate (Lewis 1983 pp 22-23). I have argued elsewhere that, depending on what is required to analyse predication, even instantiation can be analysed ontologically (Nolan 2008): but even if this is not so, this strategy arguably replaces many primitive predicates with one (or one for each grade of relation, if instantiation for properties, two-place relations, three-place relations etc. must be represented by different predicates). Even if we had to concede that unanalysed predication is unavoidable, it could still be maintained that less is better than more.

It seems to me in the spirit of Plato's position to maintain that objects are just, good, beautiful etc. because of the Forms they participate in, rather than the other way around. So if this gives a theory some genuine advantage, this is another potential resource Plato has to respond to Aristotle's challenge. It seems to me that Aristotle sees things as being the other way around: things are associated with universals because of the particular substances and accidents those things have (or are). If there is an advantage to explaining predicates of particulars through their connections to general properties and relations here, it is not available to Aristotle.

\section{Back to Plato and Aristotle}

If we can succeed in showing that postulating general properties and relations is valuable, it might seem at first sight that Plato and Aristotle can claim these virtues for the Forms and Aristotelian universals, respectively. Both can agree that we can capture generalisations about sensibles through talk about Forms/universals that are difficult to capture otherwise; both can agree that a single mathematical structure can illuminate a range of patterns in the physical world via being related to properties and relations 
instantiated in the physical world, both can agree that an account of psychology and linguistic content can be informed by citing universals. Plato at least may also have wished to take aboard and defend the tentative remarks made about reducing or doing away with primitive predication offered in the previous section. The defences mentioned may well not be the only ways to defend the usefulness and perhaps even explanatory ability of universals, but they are hopefully sufficient, when spelled out in the required detail.

In Plato's case, while these arguments would provide him with some defences of the usefulness and explanatoriness of the theory of Forms, it should be clear that they will not vindicate every use to which he put that theory. I have said nothing here of memory through metempsychosis, efficient causal explanations through the operation of the Demiurge, or various other distinctive places where Forms play a role, or appear to play a role. (How much of the views of his mouthpieces can be attributed to Plato is here, as always, a burning question - I am myself dubious that we should treat very much of Timaeus's myth-reporting as Plato's own theory, for example, despite the long tradition of doing so.)

In Aristotle's case, it is less obvious that these considerations will help him show that universals are explanatory. For Aristotle to coherently count something as an explanation he has to show that it is one of the four kinds of cause, at least if $\alpha \iota \tau \iota \alpha$ are seen as "becauses", and Aristotle is correctly interpreted as taking his four to be the only causes (in light of e.g. the passage that Tredennick translates as "these are roughly all the meanings of "cause", Metaphysics $\Delta$ 1013b, Tredennick p 213). Aristotle is also limited in apparently thinking that the aim of theorising is supplying causes (above, 992a): if that is right, then postulating entities that are not causes is at least prima facie beside the point. As we have seen Aristotle is happy to count universals as formal causes (at least when those universals are "classes" $(\gamma \varepsilon v \eta)$ which contain essential formulae). However, the issue remains whether Aristotle is entitled to do this. If the primary or ultimate formal causes (of substances, at least) are the particular essences or substances, why count the universals as well? This is particularly pressing if the universals are 
metaphysically posterior and dependent on the individual substances: it seems that the substances would explain the universals and the universals would depend on the substances, rather than the other way around. Entities seem to depend on their causes in the other senses of cause: the statue depends on the sculptor as its efficient cause, depends on its bronze material, and depends on the goal of the sculptor: why should some of its formal causes depend on it? It seems reasonable to have the statue depend on its own particular essence: but why should some class it belongs to because of its essence be a reason it is what it is?

At present I am not sure how serious this challenge is for Aristotle. It is clear he wants universals to be generic causes in at least the formal sense of cause and perhaps in others, and the challenge is to see what compelling pictures that preserve other Aristotelian themes can be constructed which allow this. Perhaps what is needed is an Aristotelian account of the causes of universals - if they are derivative from individual substances, one might expect them to be caused in some sense by those substances, and perhaps establishing room for this will preclude them from being formal causes of the substances. ${ }^{16}$ It will be important for this project to get clear on how mathematical objects contribute to causes of sensibles for Aristotle as well, since this might give us an insight to the role of mathematical universals and universals more generally. These troubles for Aristotle need not be trouble for us, however, unless we are Aristotelian enough to accept the straightjacket of an Aristotelian account of explanation in the first place.

\section{Conclusion}

If I am right, the puzzle about the point of postulating some of the abstract objects that philosophers like to invoke is one of the oldest in metaphysics. One focus of this paper has been to outline how some of the objections that Aristotle offers against the theory of Forms are connected to the more general issue of the point of employing theories of

\footnotetext{
16 An interpretation like that of Lewis 1991 avoids treating some universals, at least, as derivative from individual substances. The problems I discuss here will still arise for Lewis's Aristotle if he allows for any Aristotelian universals that are not primary substances, especially if he allows for Aristotelian universals that are not substances at all. Lewis's Aristotle also still faces the challenge presented for mathematical entities.
} 
abstract objects, whether mathematical objects or properties and relations, as well as to comment on how Plato and contemporary realists about mathematics and universals might respond to these challenges. If it turns out that it is Aristotle who faces particular difficulties here, that would be especially interesting, though more would need to be said to settle the issue of whether Aristotle can be shown to be inconsistent on this point.

There are lessons here for Aristotle interpretation (and Plato interpretation, insofar as Aristotle is one of our best sources for Plato's views other than Plato's own dialogues). There is also the lesson that some puzzles raised about mathematical platonism (e.g. by Colyvan 2001) apply to abstract metaphysical posits more generally, and may need to be addressed in similar ways. Indeed, if anything the question of how postulation of general properties and relations helps us in our theorising about particular things might be even more pressing than the question about mathematical objects, since at least everyone admits that doing mathematics is somehow very useful, whereas there is not even that much agreement about apparent talk about universals. Insofar as general properties and relations are thought to be explanatory of particular matters of fact, there is a debate to be had about them that is closely connected to the debate about whether information about abstract mathematical objects would explain non-mathematical matters. So some of the lessons of this paper are at least as much about what challenges face theories of general properties and relations, as about what the solutions to those challenges are. ${ }^{17}$

\section{Daniel Nolan}

School of Philosophy, ANU

Canberra ACT 0200

Australia

Daniel.Nolan@anu.edu.au

\section{References}

\footnotetext{
17 Thanks to audiences at ANU, Monash and the 2011 Inland Northwestern Philosophy Conference, and special thanks to Chris Daly, Jason Bowers and Michael Rota for comments, and for Karen Bennett for valuable comments as editor.
} 
Alexander of Aphrodisias. 1989. On Aristotle Metaphysics 1 (trans. Dooley W.E.). Duckworth, London.

Aristotle (trans Treddenick, H). 1933. The Metaphysics I-IX. Loeb Classical Library, William Heinemann, London. Translations from The Metaphysics quoted are the Treddenick translations except where noted.

Aristotle (trans Treddenick, H., Armstrong G.C.). 1936. The Metaphysics X-XIV, Oeconomica and Magna Moralia. Loeb Classical Library, William Heinemann, London.

Aristotle (trans Wicksteed, P and Cornford, F.M.) 1929. The Physics. Loeb Classical Library, William Heinemann, London.

Baker, A. 2005. "Are there Genuine Mathematical Explanations of Physical Facts?". Mind 114: 223-38

Bueno, O., French, L. and Ladyman, J. 2002. “On Representing the Relationship between the Mathematical and the Empirical". Philosophy of Science 69.3: 497-518

Colyvan, M. 2001. "The Miracle of Applied Mathematics". Synthese 127: 265-277

Daly, C. and Langford, S. 2009. "Mathematical Explanation and Indispensability Arguments”. Philosophical Quarterly 59.237: 641-58

Fine, G. 1984. "Separation". Oxford Studies in Ancient Philosophy 2: 31-87

Fine, G. 1993. On Ideas. Oxford University Press, New York.

French, S. 2000. "The Reasonable Effectiveness of Mathematics: Partial Structures and the Application of Group Theory to Physics". Synthese 125: 103-120 
Friedman, M. 1974. "Explanation and Scientific Understanding”. Journal of Philosophy 71: 5-19

Jenkins, C.S. and Nolan, D. 2008. "Backwards Explanation”. Philosophical Studies 140: 103-115

Kitcher, P. 1981. "Explanatory Unification”. Philosophy of Science 48: 507-531

Lewis, D. 1983. "New Work For a Theory of Universals". Reprinted in Lewis, D. 1999. Papers in Metaphysics and Epistemology. Cambridge University Press, Cambridge pp 855. Page references are to this reprint.

Lewis, D. 1986. "Causal Explanation” in Lewis, D. Philosophical Papers, Volume II. Oxford University Press, Oxford pp 214-240

Lewis, F. 1991. Substance and Predication in Aristotle. Cambridge University Press, New York.

Nolan, D. 2008. "Truthmakers and Predication". Oxford Studies in Metaphysics 4: 171192

Pap, A. 1959. "Nominalism, Empiricism and Universals-I". The Philosophical Quarterly 9.37: 330-340

Plato. Parmenides.

Plato. Phaedo.

Plato. The Sophist.

Plato. The Republic. 
Quine, W. V. 1980. “Soft Impeachment Disowned”. Pacific Philosophical Quarterly 61.4: $450-1$

Studtmann, P. 2008. “On the several senses of 'Form' in Aristotle”. Apeiron 41.3: 1-26

van Fraassen, B.C. 1980. The Scientific Image. Oxford University Press, Oxford.

Wigner, E. 1960. “The Unreasonable Effectiveness of Mathematics in the Natural Sciences". Communications in Pure and Applied Mathematics 13: 1-14. 